\title{
Calcium homeostasis behavior and cardiac function on left ventricular remodeling by pressure overload
}

\author{
I.F.S. Mazeto ${ }^{1 \oplus \bowtie}$, K. Okoshi ${ }^{2 \oplus}$, C.F.S.M.P. Silveira ${ }^{2 \oplus}$, P.G. Sant'Ana ${ }^{2 \oplus}$, V.L. da Silva ${ }^{2 \oplus}$ \\ G.A.F. Mota $^{2 \oplus}$, S.L.B. de Souza ${ }^{2 \oplus}$, D.F. Vileigas ${ }^{2 \oplus}$, C.R. Padovani ${ }^{3 \oplus}$, and A.C. Cicogna ${ }^{2 \oplus}$ \\ ${ }_{1}^{1}$ Departamento de Infectologia, Dermatologia, Diagnóstico por Imagem e Radioterapia, Faculdade de Medicina de Botucatu, \\ Universidade Estadual Paulista, Botucatu, SP, Brasil \\ ${ }^{2}$ Departamento de Clínica Médica, Faculdade de Medicina de Botucatu, Universidade Estadual Paulista, Botucatu, SP, Brasi \\ ${ }^{3}$ Departamento de Bioestatística, Instituto de Biociências, Universidade Estadual Paulista, Botucatu, SP, Brasil
}

\begin{abstract}
Sarcoplasmic reticulum $\mathrm{Ca}^{2+}$-ATPase (SERCA2a) and sarcolemmal $\mathrm{Na}^{+} / \mathrm{Ca}^{2+}$ exchanger (NCX1) structures are involved in heart cell $\mathrm{Ca}^{2+}$ homeostasis. Previous studies have shown discrepancies in their function and expression in heart failure. The goal of this study was to evaluate heart function and hypertrophied muscle $\mathrm{Ca}^{2+}$-handling protein behavior under pressure overload. Twenty male Wistar rats were divided into two groups: Aortic stenosis (AoS), induced by a clip placed at the beginning of the aorta, and Control (Sham). After 18 weeks, heart function and structure were evaluated by echocardiogram. Myocardial function was analyzed by isolated papillary muscle (IPM) at basal condition and $\mathrm{Ca}^{2+}$ protein functions were evaluated after post-pause contraction and blockage with cyclopiazonic acid in IPM. $\mathrm{Ca}^{2+}$-handling protein expression was studied by western blot (WB). Echocardiogram showed that AoS caused concentric hypertrophy with enhanced ejection fraction and diastolic dysfunction inferred by dilated left atrium and increased relative wall thickness. IPM study showed developed tension was the same in both groups. AoS showed increased stiffness revealed by enhanced resting tension, and changes in $\mathrm{Ca}^{2+}$ homeostasis shown by calcium elevation and SERCA2a blockage maneuvers. WB revealed decreased NCX1, SERCA2a, and phosphorylated phospholambam (PLB) on serine-16 in AoS. AoS had left ventricular hypertrophy and diastolic dysfunction compared to Sham; this could be related to our findings regarding calcium homeostasis behavior: deficit in NCX1, SERCA2a, and phosphorylated PLB on serine-16.
\end{abstract}

Key words: Aortic stenosis; Diastolic dysfunction; Calcium-handling proteins; Rats; Pressure

\section{Introduction}

Cardiac remodeling (CR) can be defined as changes in genetic, molecular, cellular, and interstitial expression, which can manifest as modifications in heart size, shape, and function as a response to specific aggressions, such as ischemia, inflammation, genetic mutations, and volume or pressure overload (1). CR is time-dependent and it can cause damage in the long term, representing an important risk factor for the development of ventricular dysfunction and heart failure (HF) $(2,3)$.

There are several experimental models for studying $\mathrm{CR}$, one being the pressure overload model (4-12). Pulmonary artery stenosis $(7,8)$, abdominal aortic stenosis $(9,10)$, and supravalvar aortic stenosis (AoS) $(1,3,5,6)$ are examples of interventions used to study this condition. AoS has been used to promote the gradual development of left ventricular hypertrophy in young rats $(1,3,5,6)$, with the effects appearing as weeks go by $(3,5,11,12)$.
An important component of cardiac muscle contraction is $\mathrm{Ca}^{2+}$ homeostasis. In brief, this ion, which is present in the bloodstream through diet and bone balance, enters the cell through L-type channels and is stored in the sarcoplasmic reticulum until depolarization releases it to the muscle fibers through ryanodine receptors (RyR). Afterwards, with cell repolarization, the ion is recaptured through the sarcoplasmic reticulum calcium ATPase (SERCA2a) at the expense of ATP hydrolysis (13-15). Phospholambam (PLB) is a protein that regulates SER$\mathrm{CA} 2 \mathrm{a}$, increasing its function when it is phosphorylated (16). The concentration of $\mathrm{Ca}^{2+}$ in cytosol is closely controlled, and transporters such as $\mathrm{Na}^{+}-\mathrm{Ca}^{2+}$ exchanger (NCX1) are very important in maintaining cell gradient.

Regarding heart dysfunction, echocardiogram studies by our research group found that 18 weeks after AoS induction, rats develop left atrium (LA) remodeling, concentric left 
ventricular hypertrophy, diastolic dysfunction, and systolic function maintenance, improvement, or dysfunction $(1,12)$.

Few studies have investigated $\mathrm{Ca}^{2+}$-transient proteins in experimental models of heart aggression with the above features, even though they should be considered part of the mechanisms involved in cardiac function loss. Some results in this area found that SERCA2a $(9,10)$ is reduced in AoS (11,17-19). Also, a study using rats 6 weeks after AoS found that SERCA2a is related to functional changes (11). NCX1 was enhanced in hypertrophied hearts after infarction (20) but was at normal levels shortly after pressure overload (21). Røe et al. (22) found that rats presented enhanced SERCA and NCX1 activity after 6 weeks of aortic banding. They also concluded that LV complacency was altered regardless of changes in $\mathrm{Ca}^{2+}$ homeostasis. Rouhana et al. (23) showed that normal SERCA and NCX1 levels after 4 weeks increased phosphorylated PLB on threonine-17; $\mathrm{Ca}^{2+}$ was enhanced due to a lower extrusion through NCX1 and a larger leak from the sarcoplasmic reticulum through RyR. HadipourLakmehsari et al. (24) reported that, after 8 weeks of transverse aortic constriction, RyR was reduced, SERCA enhanced, and PLB decreased after 2 weeks but was similar to Sham after 4 weeks.

Due to these divergent results on cardiac performance in left ventricular pressure overload remodeling and the function and expression of intracellular $\mathrm{Ca}^{2+}$-related proteins in non-transgenic animals, we decided to perform this study to evaluate cardiac function 18 weeks after AoS and to test whether functional variation of these proteins participates in hypertrophied muscle performance changes.

\section{Material and Methods}

\section{Animal care}

Twenty 30 -day-old male Wistar rats weighting between 60 and $80 \mathrm{~g}$ were obtained from the Animal Center of Botucatu Medical School, São Paulo State University, UNESP (Brazil). All experiments and procedures were performed in accordance with the Guide for the Care and Use of Laboratory Animals published by the National Research Council (1996) and were approved by Botucatu Medical School Ethics Committee (protocol FMB-PE-30/ 2013). The rats were housed $4 /$ cage in a controlled environment (12-h light/dark cycle starting at 6:00 am) and clean-air room temperature $\left(23^{\circ} \mathrm{C}\right)$. They received food and water ad libitum and body weight (BW) was measured weekly.

\section{Experimental protocol}

Groups. The two groups consisted of: AoS, 17 rats implanted with supravalvar bands, and Sham, 13 rats submitted to similar surgery but without band implant. During the study, 3 Sham and 5 AoS rats died. After applying the exclusion criteria below, each group contained 10 animals each.
Aortic stenosis surgery. Rats were anesthetized with intraperitoneal ketamine (50 mg/kg, ip) and xylazine hydrochloride $(10 \mathrm{mg} / \mathrm{kg}, \mathrm{ip})$. A thoracotomy was performed and a silver band (0.6-0.7 mm internal diameter) was placed around the ascending aorta, as previously described $(11,12,25-28)$. Exclusion criteria were evidence of heart failure.

In vivo functional and structural studies. All rats were submitted to echocardiographic evaluation 2-4 days before euthanasia using a Philips ${ }^{\circledR}$ HDI 5000 apparatus (Philips Electronics North America Corporation, USA) to evaluate performance and the effects of surgery (29-35). Rats were anesthetized with a mixture of ketamine (50 mg/kg, ip) and xylazine hydrochloride (10 mg/kg, ip). Structural variables were measured: LV diastolic diameter (LVDD), LV diastolic posterior wall thickness (DPWT), relative wall thickness (RWT), left atrium diameter (LA), and aortic diameter (AO). LV function was assessed by heart rate $(H R)$, ejection fraction $(E F)$, midwall fractional shortening (FS), early and late diastolic mitral inflow velocities ( $E$ and $A$ waves), E/A ratio, $E$ wave deceleration time (EDT), and LV isovolumetric relaxation time (IVRT).

In vitro functional study: isolated papillary muscle. Rats were euthanized 18 weeks after surgery to harvest the heart, isolated papillary muscle (IPM), and the lungs. Animals were anesthetized with sodium pentobarbital (50 mg/kg, ip), euthanized, submitted to a thoracotomy, and the hearts were quickly removed and placed in oxygenated Krebs-Henseleit solution at $28^{\circ} \mathrm{C}$. Papillary muscle was dissected carefully from the left ventricle, clipped at its edges, placed vertically in a chamber containing Krebs-Henseleit solution at $28^{\circ} \mathrm{C}$, oxygenated with a mixture of $0.95 \mathrm{O}_{2}$ and $0.5 \mathrm{CO}_{2}(\mathrm{pH} 7.38)$, and stimulated with two electrodes in the solution at a rate of $0.2 \mathrm{~Hz}$. Papillary muscle performance was evaluated by a technique often used in our laboratory (11,36-38). The following basal parameters were measured from isometric contraction: peak developed tension (DT, g/mm ${ }^{2}$ ), resting tension $\left(R T, g / \mathrm{mm}^{2}\right)$, time to peak tension (TPT, ms), maximum rate of tension development ( $+\mathrm{dT} / \mathrm{dt}, \mathrm{g} / \mathrm{mm}^{2}$ per $\left.\mathrm{s}\right)$, and maximum rate of tension decline $\left(-\mathrm{dT} / \mathrm{dt}, \mathrm{g} / \mathrm{mm}^{2}\right.$ per $\left.\mathrm{s}\right)$. The mechanical behavior of papillary muscle was evaluated at baseline condition with extracellular calcium $\left(\mathrm{Ca}^{2+}\right)$ concentration of $2.5 \mathrm{mM}$. Then, the following inotropic maneuvers were performed: post-rest contraction, with $\mathrm{Ca}^{2+}=0.5 \mathrm{mM}$; gradual $\mathrm{Ca}^{2+}$ elevation from 0.5 to $2.5 \mathrm{mM}$, to evaluate $\mathrm{Ca}^{2+}$ intake; and SERCA2a blockage by cyclopiazonic acid (CPA), as previously described $(11,39)$.

The contractions were registered using a computer data system (AcqKnowledge ${ }^{\circledR}$ MP100, Biopac Systems, Inc., USA).

Papillary muscle cross-sectional area (CSA, $\mathrm{mm}^{2}$ ) was calculated from muscle weight and length by assuming cylindrical uniformity and a specific gravity of 1.0. All force data were normalized for muscle CSA. Papillary muscles 
with CSA $<0.5$ and $>1.5 \mathrm{~mm}^{2}$ were excluded from analysis.

Western blot study. Myocardial protein expression of SERCA2a, PLB, NCX1, RyR, and L-type $\mathrm{Ca}^{2+}$ channel in both groups were evaluated by western blot analysis according to the currently accepted procedure (38). Briefly, a total of $50 \mu \mathrm{g}$ protein lysate was resolved by SDS-PAGE and transferred to a nitrocellulose membrane (Armsham Biosciences, USA) through transblot (semi-dry) to all proteins except L-type channel and ryanodine (wet transfer) with primary antibodies against SERCA2 ATPase (Affinity BioReagebts, USA), phospho-phospholambam (Affinity BioReagebts), phospho-phospholambam Ser16 and Thr17 (Badrilla, UK), exchanger $\mathrm{Na}^{+} / \mathrm{Ca}^{2+}$ (NCX1, Upstate, USA), calcium channel voltage gated alpha $1 \mathrm{C}$ (Chemicon International, USA), ryanodine receptor (Affinity BioReagents), and $\beta$-actin (Cell Signaling Technology \#4967S, USA).

Post mortem morphological analysis. The presence of ventricular and atrial hypertrophy was determined by analyzing BW, tibia length (TB), and the ratio between left ventricle (LV), right ventricle (RV), atrium (AT), and total heart $(\mathrm{TH})$ per TB. Water in the lungs was evaluated by measuring lung weight/TB ratio.

\section{Statistical analysis}

Data from cardiac function and morphology in vivo and in vitro, basal isometric contraction, and western blot are reported as means $\pm S D$, and comparisons between groups were performed using the Student's $t$-test for independent samples. Inotropic maneuvers are reported as median, minimum, and maximum or as means $\pm S D$, using different methods of variance analysis for repeated measures. Muscle length was compared with RT and DT by the least squares method (39). The level of significance was 0.05 . Normality test was performed.

\section{Results}

Post-mortem (Table 1) and echocardiographic (Table 2) structural studies showed that the AoS group had a remodeled RV and AT. The LV had a concentric hypertrophy. Echocardiographic functional analysis (Table 3) showed an improvement in systolic function (EF, FS). Diastolic functional variables did not show any change compared to Sham. However, if we consider the fact that there was an increase in relative wall thickness and LA dimensions, it is possible to infer that LV had diastolic dysfunction.

In vitro papillary muscle functional study at basal condition (Table 4) showed increased RT in AoS muscle compared to the Sham group. This behavior was also seen in the relationship between RT and muscle length variation (Figure 1). These data showed that hypertrophied muscle is more rigid than the control, suggesting diastolic dysfunction, which corroborates the assumption
Table 1. Post-mortem structural study of animals submitted to simulated surgery (Sham) and animals submitted to aortic stenosis surgery (AoS).

\begin{tabular}{lccc}
\hline & Sham & Aos & P \\
\hline BW $(\mathrm{g})$ & $470 \pm 36$ & $479 \pm 73$ & 0.74 \\
TB $(\mathrm{cm})$ & $4.34 \pm 0.12$ & $4.30 \pm 0.09$ & 0.35 \\
LV/TB & $0.20 \pm 0.01$ & $0.31 \pm 0.02$ & $<0.001$ \\
RV/TB & $0.055 \pm 0.004$ & $0.061 \pm 0.008$ & 0.04 \\
AT/TB & $0.023 \pm 0.002$ & $0.04 \pm 0.01$ & $<0.001$ \\
TH/TB & $0.28 \pm 0.02$ & $0.41 \pm 0.03$ & $<0.001$ \\
LUNGS/TB & $0.41 \pm 0.05$ & $0.43 \pm 0.07$ & 0.58 \\
\hline
\end{tabular}

Data are reported as means $\pm S D$ ( $n=10 /$ group). AoS vs Sham, Student's $t$-test. BW: body weight; TB: tibia length; LV: left ventricle; RV: right ventricle; $\mathrm{AT}$ : atria; $\mathrm{TH}$ : total heart

Table 2. Structural study by echocardiogram.

\begin{tabular}{lccc}
\hline & Sham & AoS & P \\
\hline LVDD $(\mathrm{mm})$ & $8.64 \pm 0.46$ & $7.76 \pm 0.29$ & $<0.001$ \\
LVDD/TB $(\mathrm{mm} / \mathrm{cm})$ & $1.99 \pm 0.10$ & $1.81 \pm 0.06$ & $<0.001$ \\
DPWT $(\mathrm{mm})$ & $1.50 \pm 0.11$ & $1.90 \pm 0.22$ & $<0.001$ \\
RWT & $0.35 \pm 0.03$ & $0.49 \pm 0.06$ & $<0.001$ \\
LA $(\mathrm{mm})$ & $5.86 \pm 0.47$ & $6.68 \pm 0.65$ & 0.005 \\
LA/TB $(\mathrm{mm} / \mathrm{cm})$ & $1.35 \pm 0.10$ & $1.56 \pm 0.16$ & 0.003 \\
LA/AO & $1.49 \pm 0.17$ & $1.68 \pm 0.21$ & 0.04 \\
\hline
\end{tabular}

Data are reported as means $\pm S D$ ( $n=10$ /group). AoS vs. Sham, Student's $t$-test. Sham: control group submitted to surgery without clipping, AoS: aortic stenosis group submitted to surgery with clipping, $n=10$; LVDD: left ventricle diastolic diameter; TB: tibia length; DPWT: diastolic posterior wall thickness; RWT: relative wall thickness; LA: left atrium diameter; AO: aorta diameter.

Table 3. Functional study by echocardiogram of animals submitted to simulated surgery (Sham) and animals submitted to aortic stenosis surgery (AoS).

\begin{tabular}{lccr}
\hline & Sham & AoS & \multicolumn{1}{c}{$P$} \\
\hline HR $(\mathrm{bpm})$ & $243 \pm 12$ & $273 \pm 25$ & 0.003 \\
EF $(\%)$ & $0.86 \pm 0.02$ & $0.93 \pm 0.04$ & $<0.001$ \\
FS $(\%)$ & $28.23 \pm 1.95$ & $34.77 \pm 4.88$ & 0.001 \\
E $(\mathrm{cm} / \mathrm{s})$ & $82.20 \pm 9.83$ & $89.10 \pm 16.81$ & 0.28 \\
A $(\mathrm{cm} / \mathrm{s})$ & $51.90 \pm 6.97$ & $60.50 \pm 17.95$ & 0.17 \\
E/A & $1.60 \pm 0.25$ & $1.56 \pm 0.42$ & 0.76 \\
EDT $(\mathrm{ms})$ & $44.00 \pm 5.83$ & $37.56 \pm 7.89$ & 0.06 \\
IVRT $(\mathrm{ms})$ & $26.60 \pm 2.99$ & $23.50 \pm 4.55$ & 0.09 \\
\hline
\end{tabular}

Data are reported as means $\pm S D(n=10 /$ group). AoS vs Sham, Student's $t$-test. HR: heart rate; EF: ejection fraction; FS: midwall fraction shortening; $E / A$ : ratio between filling flow peak ( $E$ wave) and atrial contraction flow peak (A wave); EDT: $E$ wave deceleration time; IVRT: left ventricular isovolumetric relaxation time. 
Table 4. Basal isometric contraction of animals submitted to simulated surgery (Sham) and animals submitted to aortic stenosis surgery (AoS).

\begin{tabular}{lccl}
\hline & Sham & AoS & P \\
\hline DT $\left(\mathrm{g} / \mathrm{mm}^{2}\right)$ & $5.91 \pm 0.98$ & $6.20 \pm 1.66$ & 0.65 \\
RT $\left(\mathrm{g} / \mathrm{mm}^{2}\right)$ & $0.64 \pm 0.18$ & $0.86 \pm 0.21$ & 0.02 \\
$+\mathrm{dT} / \mathrm{dt}\left(\mathrm{g} / \mathrm{mm}^{2}\right.$ per s $)$ & $68.70 \pm 12.64$ & $62.37 \pm 14.25$ & 0.31 \\
-dT/dt $\left(\mathrm{g} / \mathrm{mm}^{2}\right.$ per s) & $26.35 \pm 4.26$ & $27.49 \pm 8.13$ & 0.70 \\
TPT $(\mathrm{ms})$ & $166 \pm 21$ & $192 \pm 14$ & 0.005 \\
CSA $\left(\mathrm{mm}^{2}\right)$ & $1.06 \pm 0.21$ & $1.20 \pm 0.22$ & 0.18 \\
\hline
\end{tabular}

Data are reported as means $\pm S D(n=10 /$ group). AoS vs Sham; Student's $t$-test. Extracellular calcium concentration: $2.5 \mathrm{mM}$. DT: maximum developed tension; RT: resting tension; + dT/dt: maximum rate of tension development; $-\mathrm{dT} / \mathrm{dt}$ : maximum rate of tension decline; TPT: time-to-peak tension; CSA: cross-sectional area.

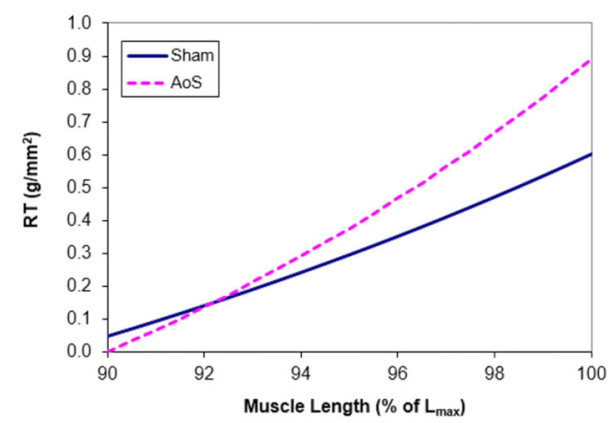

Figure 1. Relationship between muscle length variation, in \% of maximum length $\left(L_{\max }\right)$, and resting tension (RT). $P<0.01$, Sham vs aortic stenosis (AoS) (non-linear regression model adjustment using the least squares method).

from the echocardiographic study. Systolic function remained the same in both groups (Table 4 and Figure 2), which differs from the in vivo study, where it showed an improvement in the hypertrophied heart. TPT was increased in AoS animals.

Calcium elevation effects are shown in Figure 3. This maneuver revealed a significant difference between the two groups, although there is no distinction between moments in each group. AoS had significantly less response to increased extracellular $\mathrm{Ca}^{2+}$ concentration compared to controls.

Differently from the $\mathrm{Ca}^{2+}$ elevation maneuver, no divergence in post-rest contraction was seen between groups (Figure 4), only between different moments. Although DT and -dT/dt increased from moment 10" to 60", +dT/dt was statistically divergent after 30 " in both groups.

CPA blockage (Figure 5), which is also used to analyze SERCA2a behavior, showed a difference between AoS and Sham groups for +dT/dt $(2.5 \mathrm{mM})$ and $-\mathrm{dT} / \mathrm{dt}$ (1.5 and $2.5 \mathrm{mM}$ ), which differed from the post-rest

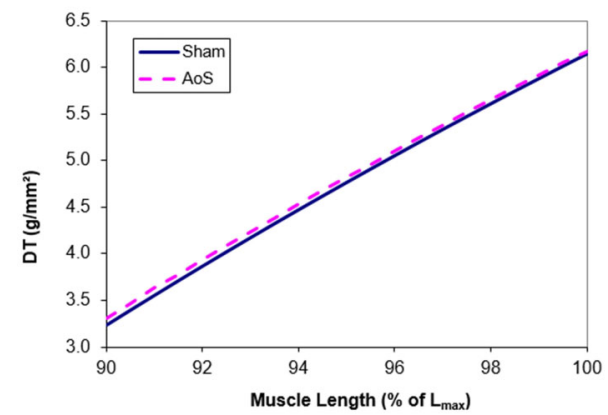

Figure 2. Relationship between muscle length variation, in \% of maximum length $\left(L_{\max }\right)$, and developed tension (DT). AoS: aortic stenosis.

contraction study. Hypertrophied muscle presented lower contraction and relaxation speeds than control rats at these same moments in SERCA2a blockage maneuver.

To complement $\mathrm{Ca}^{2+}$ intracellular transient analysis, we investigated the expression of proteins involved in this phenomenon. Of the studied parameters (Figure 6), only NCX1 and SERCA2a showed decreases in hypertrophied heart compared to controls. SERCA2a/PLB and phosphorylated PLB serine 16/PLB ratios were also reduced. These data supported the hypothesis that the proteins related to intracellular $\mathrm{Ca}^{2+}$ homeostasis were affected in hearts under pressure overload.

\section{Discussion}

It is known that when the heart is submitted to a pressure overload, such as aortic banding, its response is enhanced contractile strength, generating a thicker ventricle wall and smaller chamber diameter. In its early stages, this process helps to maintain the correct operation of the cardiovascular system, however, over time it will damage the heart and its function will fail $(11,12,25)$.

Our echocardiography showed that after 18 weeks of aortic stenosis animals presented concentric hypertrophy, diastolic dysfunction, and increased systolic function. This result was in agreement with literature that shows enhanced systolic function after 18 weeks (12). On the other hand, Mendes et al., using the same methodology and observation time, found an initial decrease after 18 weeks (1) in AoS. Although our study found no statistical difference between the variables that analyze diastolic function in echocardiogram, the increase in relative wall thickness implies in hypertrophy, which impairs muscle energy balance, jeopardizing diastole, and increasing end diastolic pressure, which ends up leading to left atrium enlargement, also found in our study. Literature shows that diastolic dysfunction is usually found in this experimental cardiopathy model after 6 weeks of aortic stenosis $(11,12,25)$. 

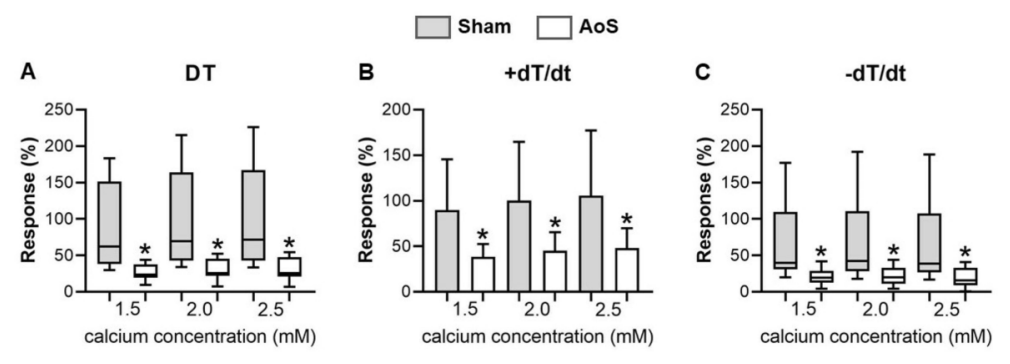

Figure 3. Percent calcium elevation from baseline $\left(\mathrm{Ca}^{2+}\right.$ concentration: $\left.0.5 \mathrm{mM}\right)$. DT: maximum developed tension; $+\mathrm{dT} / \mathrm{dt}$ : maximum rate of tension development; $-\mathrm{dT} / \mathrm{dt}$ : maximum rate of tension decline. Sham: animals submitted to simulated surgery ( $n=10)$; AoS: animals submitted to aortic stenosis surgery $(n=10)$. Data are reported as median, maximum, and minimum $(\mathbf{A}$ and $\mathbf{C})$, or means $\pm S D$ (B). ${ }^{*} \mathrm{P}<0.05$, Sham vs AoS [analysis of variance for repeated measures and Bonferroni post hoc test (bar chart) or Kruskall Wallis and Wilcoxon tests complemented by Dunn post hoc test (box plot)].

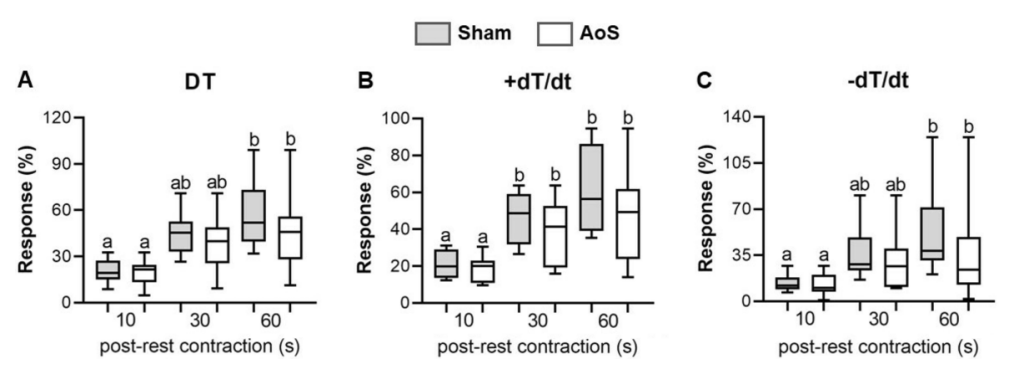

Figure 4. Percent of post-rest contraction from baseline $\left(\mathrm{Ca}^{2+}\right.$ concentration: $\left.0.5 \mathrm{mM}\right)$. DT: maximum developed tension; $+\mathrm{dT} / \mathrm{dt}$ : maximum rate of tension development; $-\mathrm{dT} / \mathrm{dt}$ : maximum rate of tension decline. Sham: animals submitted to simulated surgery $(n=10)$; AoS: animals submitted to aortic stenosis surgery $(n=10)$. Data are reported as median, maximum, and minimum. $P<0.05$, Sham vs AoS (Kruskall Wallis and Wilcoxon tests complemented by Dunn post hoc test). Different letters indicate statistical difference among the moments within each group.

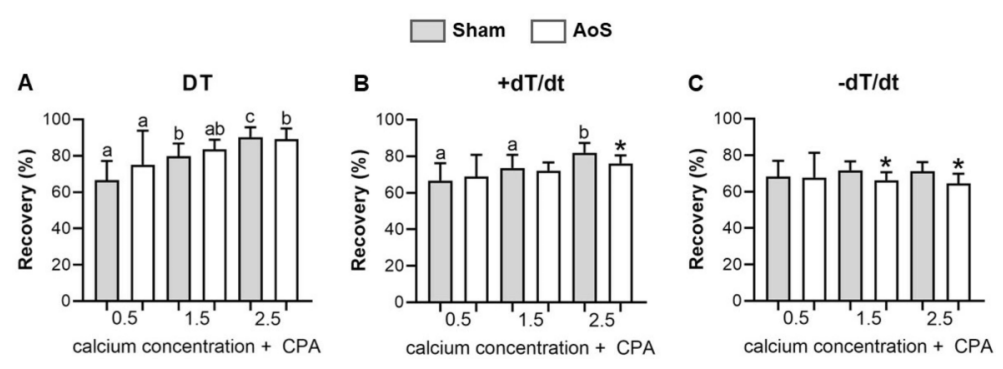

Figure 5. Function recovery in percentage post cyclopiazonic acid (CPA). DT: maximum developed tension; +dT/dt: maximum rate of tension development; $-\mathrm{dT} / \mathrm{dt}$ : maximum rate of tension decline. Sham: animals submitted to simulated surgery $(n=10)$; AoS: animals submitted to aortic stenosis surgery $(n=10)$. Data are reported as means $\pm S D$. ${ }^{*} P<0.05$, AoS vs Sham (analysis of variance for repeated measures and Bonferroni post hoc test). Different letters indicate statistical difference among the moments within each group.

We studied isolated papillary muscle to verify whether the alterations in hypertrophied muscle seen in vivo were still present even under controlled conditions such as in vitro preload, afterload, and heart rate. We also analyzed whether the calcium transient misbalance could be one of the mechanisms involved in this experimental heart failure model.
The data were partially compatible with echocardiogram. RT was elevated, both at basal condition and during muscle length variation, proving that AoS animals had lower heart muscle complacency, which indicates diastolic dysfunction. According to Silveira et al. (11), one factor that could explain this finding is an increase in cytosolic $\mathrm{Ca}^{2+}$ at the end of the diastole, leaving ions bound to $C$ troponin. 

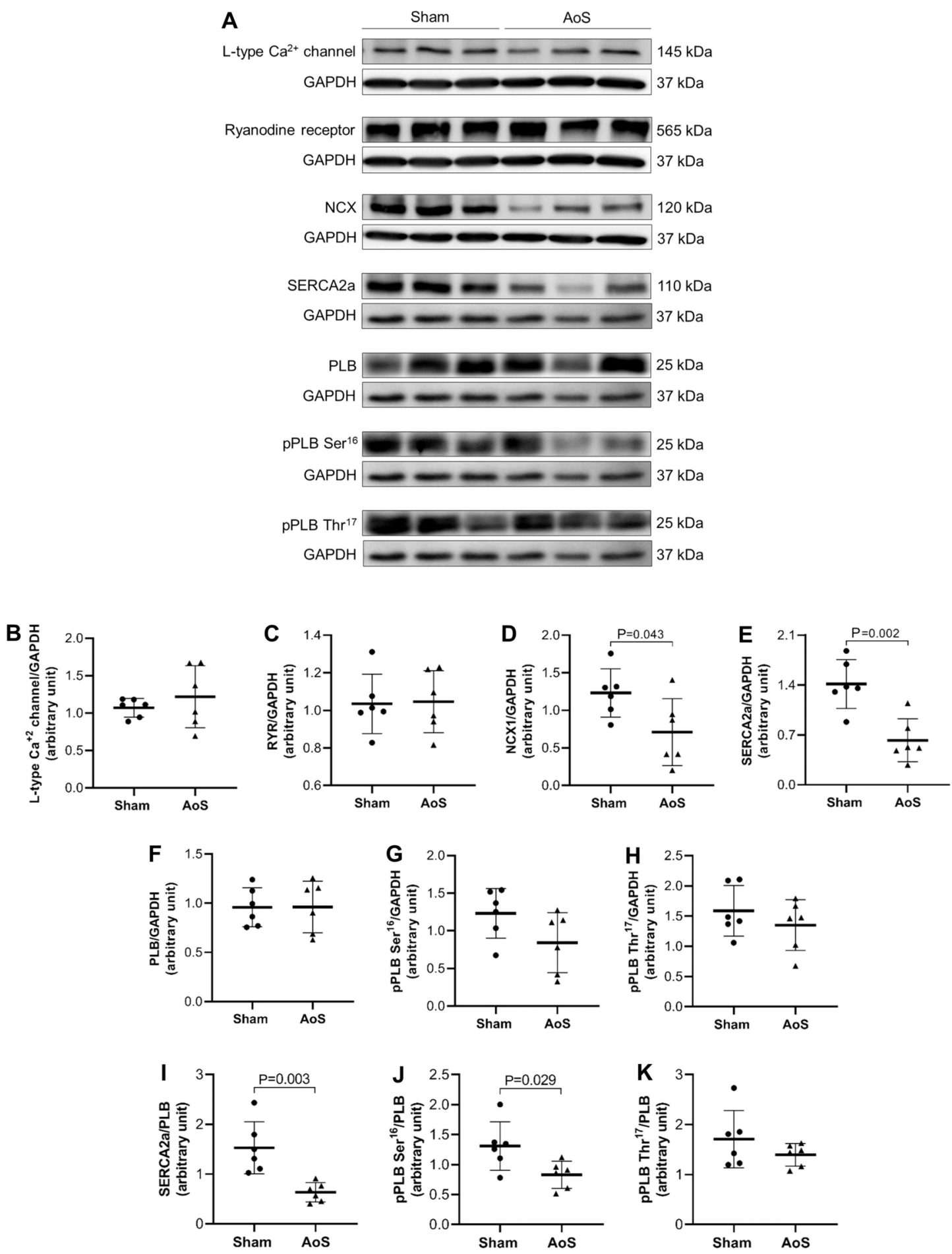

Figure 6. Western blot analysis of intracellular $\mathrm{Ca}^{2+}$-cycling proteins in myocardium from Sham and aortic stenosis $($ AoS) rats $(n=6$ in each group). A, Representative bands of the proteins. Quantification of myocardial (B) L-Type Ca ${ }^{2+}$ channel, (C) ryanodine receptor (RyR), (D) $\mathrm{Na}^{+} / \mathrm{Ca}^{2+}$ exchanger (NCX1), (E) sarcoplasmic reticulum calcium-ATPase (SERCA2a), (F) total phospholamban (PLB), (G) phosphorylated PLB on serine-16 (pPLB Ser16), and (H) phosphorylated PLB on threonine-17 (pPLB Thr17) normalized to glyceraldehyde 3-phosphate dehydrogenase (GAPDH). Quantification of (I) SERCA2a, (J) pPLB Ser16, and (K) pPLB Thr17 normalized to total PLB. Data are reported as means $\pm S D$. $P<0.05$, Student's $t$-test. 
However, although the image exam showed enhanced systolic function, DT in this study was similar in both groups. Higher TPT in AoS could indicate the beginning of mechanical systolic dysfunction, which was not detected in the echocardiogram. This behavioral distinction is probably due to the fact that papillary muscle is analyzed in situations with controlled load and heart rate and is free from neurohumoral variations, present in in vivo heart.

The inotropic maneuvers used in our papillary muscle study showed that dysfunctional hypertrophied myocardium may be related to calcium-handling alterations. Thus, elevated extracellular calcium concentrations displayed a robust difference in behavior between groups, with aortic stenosis animals presenting less response to an increase in this ion. This pronounced change did not appear in postrest contraction maneuver but was present at a lower level in SERCA2a blockage with cyclopiazonic acid. These results suggested a dysfunction in $\mathrm{Ca}^{2+}$ entry through L-type $\mathrm{Ca}^{2+}$ channels, although expression was normal in the molecular study. There was also less damage of the intracellular $\mathrm{Ca}^{2+}$ cycle in the myocardium, which could be compatible with decreased SERCA2a and SERCA2a/PLB expression.

The decrease in NCX1 expression, the most important mechanism involved in calcium efflux across the plasma membrane, would allude to enhanced intracellular $\mathrm{Ca}^{2+}$ in

\section{References}

1. Mendes OC, Campos DHS, Damatto RL, Sugizaki MM, Padovani CR, Okoshi K, et al. Cardiac remodeling: serial analysis and indexes for early detection of ventricular dysfunction [in Portuguese]. Arq Bras Cardiol 2010; 94: 62-70, doi: 10.1590/S0066-782X2010000100011.

2. Cicogna AC, Okoshi MP, Okoshi K. História natural da remodelação miocárdica: da agressão aos sintomas [in Portuguese]. Rev Soc Cardiol do Estado de São Paulo. 2000; 10: 8-16.

3. Boluyt MO, Robinson KG, Meredith AL, Sem S, Lakatta EG, Crow MT, et al. Heart failure after long-term supravalvar aortic constriction in rats. Am J Hypertens 2005; 18: 202212, doi: 10.1016/j.amjhyper.2004.08.034.

4. Okoshi MP, Matsubara LS, Franco M, Cicogna AC, Matsubara BB. Myocyte necrosis is the basis for fibrosis in renovascular hypertensive rats. Braz J Med Biol Res 1997; 30: 1135-1144, doi: 10.1590/S0100-879X199700090 0013.

5. Mestrinel MA. Avaliação morfológica, bioquímica e funcional do remodelamento cardíaco desencadeado por sobrecarga pressórica em ratos com e sem insuficiência cardíaca congestiva [Thesis; in Portuguese]. Botucatu: Faculdade Medicina, Universidade Estadual Paulista. 2003.

6. Ribeiro HB, Okoshi K, Cicogna AC, Bregagnollo EA, Rodrigues MAM, Padovani CR, et al. Estudo evolutivo da morfologia e função cardíaca em ratos submetidos a estenose aórtica supravalvar [in Portuguese]. Arq Bras Cardiol 2003; 81: 562-568, doi: 10.1590/S0066-782X2003 001400003. hypertrophied muscle, which corroborates the idea that remaining ions cause the diastolic dysfunction shown in IPM through an elevation in resting tension.

An interesting review looked at $\mathrm{Ca}^{2+}$-handling proteins and their relationship with hypertrophied muscle (40). In several studies, Locatelli et al. (40) found that NCX1 is usually enhanced in heart failure and hypertrophy and that SERCA expression is reduced or regulator levels are increased. This review only corroborates all the divergences between studies and between data within studies that are cited in the present article. Perhaps variables such as similarity between animals, experiment conditions, and evaluator performances have a huge influence on results; that is why scientific research needs to continue in its quest for an answer.

In conclusion, data in our study showed that 18 weeks after AoS surgery rats presented diastolic dysfunction, which could be related to changes in calcium-homeostasis behavior.

\section{Acknowledgments}

We would like to acknowledge FAPESP (Fundação de Amparo à Pesquisa do Estado de São Paulo) for their financial support (grants 2011/21366-8 and 2013/098 30-6), and Dijon H.S. de Campos for technical assistance.

7. Matsui H, MacLennan DH, Alpert NR, Periasamy M. Sarcoplasmic reticulum gene expression in pressure overload-induced cardiac hypertrophy in rabbit. Am J Physiol 1995; 268: C252-C258, doi: 10.1152/ajpcell.1995.268.1. C252.

8. Rockman HA, Ono S, Ross RS, Jones LR, Karimi M, Bhargava $\mathrm{V}$, et al. Molecular and physiological alterations in murine ventricular dysfunction. Proc Natl Acad Sci USA 1994; 91: 2694-2698, doi: 10.1073/pnas.91.7.2694.

9. Tsutsui $H$, Ishibashi $Y$, Imanaka-Yoshida K, Yamamoto S, Yoshida T, Sugimachi M, et al. Alterations in sarcoplasmic reticulum calcium-storing proteins in pressure-overload cardiac hypertrophy. Am J Physiol 1997; 272: H168-H175, doi: 10.1152/ajpheart.1997.272.1.H168.

10. De la Bastie D, Levitsky D, Rappaport L, Mercadier JJ, Marotte F, Wisnewsky C, et al. Function of the sarcoplasmic reticulum and expression of its $\mathrm{Ca} 2(+)$-ATPase gene in pressure overload-induced cardiac hypertrophy in the rat. Circ Res 1990; 66: 554-564, doi: 10.1161/01.RES.66.2.554.

11. Silveira CFSMP, Campos DHS, Freire PP, Deus AF, Okoshi $\mathrm{K}$, Padovani CR, et al. Importance of SERCA2a on early isolated diastolic dysfunction induced by supravalvular aortic stenosis in rats. Braz J Med Biol Res 2017; 50: e5742, doi: 10.1590/1414-431x20175742.

12. De Tomasi LC, Campos DHS, Sant'Ana PG, Okoshi K, Padovani CR, Murata GM, et al. Pathological hypertrophy and cardiac dysfunction are linked to aberrante endogenous unsaturated fatty acid metabolism. PLoS One 2018; 13 : e0193553, doi: 10.1371/journal.pone.0193553. 
13. Hiranandani N, Raman S, Kalyanasundaram A, Periasamy $M$, Janssen PML. Frequency-dependent contractile strength in mice over- and underexpressing the sarco (endo)plasmic reticulum calcium-ATPase. Am J Physiol Regul Integr Comp Physiol 2007; 293: R30-R36, doi: 10.1152/ajpregu.00508. 2006.

14. Periasamy M, Huke S. SERCA pump level is a critical determinant of $\mathrm{Ca}(2+)$ homeostasis and cardiac contractility. J Mol Cell Cardiol 2001; 33: 1053-1063, doi: 10.1006/ jmcc.2001.1366.

15. Arai M, Alpert NR, MacLennan DH, Barton P, Periasamy M. Alterations in sarcoplasmic reticulum gene expression in human heart failure. A possible mechanism for alterations in systolic and diastolic properties of the failing myocardium. Circ Res 1993; 72: 463-469, doi: 10.1161/01.RES.72.2.463.

16. Freire PP, Alves CAB, Deus AF, Leopoldo APL, Leopoldo AS, Silva DCT, et al. Obesidade não Acarreta Desequilíbrio entre Fosforilação e Desfosforilação da Fosfolambam Miocárdica. Arq Bras Cardiol 2014; 103 no.1 São Paulo, doi: 10.5935/abc.20140083.

17. Tanaka N, Dalton N, Mao L, Rockman HÁ, Peterson KL, Gottshall KR, et al. Transthoracic echocardiography in models of cardiac disease in the mouse. Circulation 1996; 94: 1109-1117, doi: 10.1161/01.CIR.94.5.1109.

18. Feldman AM, Weinberg EO, Ray PE, Lorell BH. Selective changes in cardiac gene expression during compensated hypertrophy and the transition to cardiac decompensation in rats with chronic aortic banding. Circ Res 1993; 73: 184192, doi: 10.1161/01.RES.73.1.184.

19. Miyamoto MI, del Monte F, Schmidt U, DiSalvo TS, Kang ZB, Matsui $\mathrm{T}$, et al. Adenoviral gene transfer of SERCA2a improves left-ventricular function in aortic-banded rats in transition to heart failure. Proc Natl Acad SCi USA 2000; 97: 793-798, doi: 10.1073/pnas.97.2.793.

20. Holtz J. Myocardial hypertrophy after myocardial infarct: what is the significance of phenotype changes in cardiocytes? [in German]. Herz 1993; 18: 387-394.

21. Carnicelli V, Frascarelli S, Ghelardoni S, Ronca-Testoni S, Zucchi R. Short-term effects of pressure overload on the expression of genes involved in calcium homeostasis. Mol Cell Biochem 2008; 313: 29-36, doi: 10.1007/s11010-0089738-0.

22. Røe AT, Aronsen JM, Skardal K, Hamdani N, Linke WA, Danielsen HE, et al. Increased passive stiffness promotes diastolic dysfunction despite improved $\mathrm{Ca} 21$ handling during left ventricular concentric hypertrophy. Cardiovasc Res 2017; 113, 1161-1172, doi: 10.1093/cvr/cvx087.

23. Rouhana S, Farah C, Roy J, Finan A, Araujo GR, Bideaux P, et al. Early calcium handling imbalance in pressure overload-induced heart failure with nearly normal left ventricular ejection fraction. Biochim Biophys Acta Mol Basis Dis 2019; 1865: 230-242, doi: 10.1016/j.bbadis.2018. 08.005 .

24. Hadipour-Lakmehsari S, Driouchi A, Lee SH, Kuzmanov U, Callaghan $\mathrm{NI}$, Heximer SP, et al. Nanoscale reorganization of sarcoplasmic reticulum in pressureoverload cardiac hypertrophy visualized by dSTO RM. Sci Rep 2019; 9: 7867, doi: 10.1038/s41598-019-44331-y.

25. Mendes OC, Sugizaki MM, Campos DS, Damatto RL, Leopoldo AS, Lima-Leopoldo AP, et al. Exercise tolerance in rats with aortic stenosis and ventricular diastolic and/or systolic dysfunction. Arq Bras Cardiol 2013; 100: 44-51, doi: 10.1590/S0066-782X2012005000112.

26. Gonçalves G, Zornoff LAM, Ribeiro HB, Okoshi MP, Cordaro FRS, Okoshi $\mathrm{K}$, et al. Blockade of renin-angiotensin system attenuates cardiac remodeling in rats undergoing aortic stenosis [in Portuguese]. Arq Bras Cardiol 2005; 84: 304-308, doi: 10.1590/S0066-782X2005000400006.

27. Okoshi K, Ribeiro HB, Okoshi MP, Matsubara BB, Gonçalves G, Barros R, et al. Improved systolic ventricular function with normal myocardial mechanics in compensated cardiac hypertrophy. Jpn Heart J 2004; 45: 647-656, doi: 10.1536/jhj.45.647.

28. Carvalho RF, Cicogna AC, Campos Ge, De Assis JM, Padovani CR, Okoshi MP, et al. Myosin heavy chain expression and atrophy in rat skeletal muscle during transition from cardiac hypertrophy to heart failure. Int $J$ Exp Pathol 2003; 84: 201-206, doi: 10.1046/j.1365-2613. 2003.00351.x.

29. Cicogna AC, Padovani CR, Georgette JC, Aragon FF, Okoshi MP. Efeito da restrição protéico-calórica sobre a função mecânica dos músculos cardíacos hipertrofiados. Arq Bras Cardiol 1999; 72: 431-435, doi: 10.1590/S0066782X1999000400004.

30. Guazzi M, Brenner DA, Apstein CS, Saupe KW. Exercise intolerance in rats with hypertensive heart disease is associated with impaired diastolic relaxation. Hypertension 2001 ; 37: 204-208, doi: 10.1161/01.HYP.37.2.204.

31. de Paiva SA, Zornoff LA, Okoshi PM, Okoshi K, Matsubara LS, Matsubara BB, et al. Ventricular remodeling induced by retinoic acid supplementation in adult rats. Am J Physiol Heart Circ Physiol 2003 ; 284: H2242-H2246, doi: 10.1152/ ajpheart.00646.2002.

32. Bayat H, Swaney JS, Ander AN, Dalton N, Kennedy BP, Hammond $\mathrm{HK}$, et al. Progressive heart failure after myocardial infarction in mice. Basic Res Cardiol 2002; 97: 206-213, doi: 10.1007/s003950200013.

33. Sjaastad I, Sejersted OM, llebekk A, Bjornerheim R. Echocardiographic criteria for detection of postinfarction congestive heart failure in rats. J Appl Physiol 2000; 89: 1445-1454, doi: 10.1152/jappl.2000.89.4.1445.

34. Ono K, Masuyama T, Yamamoto $\mathrm{K}$, Doi $\mathrm{R}$, Sakata $\mathrm{Y}$, Nishikawa $N$, et al. Echo Doppler assessment of left ventricular function in rats with hypertensive hypertrophy. J Am Soc Echocardiogr 2002; 15: 109-117, doi: 10.1067/ mje.2002.115034.

35. Cantor EJF, Babick AP, Vasanji Z, Dhalla NS, Netticadan T. A comparative serial Echocardiographic analysis of cardiac structure and function in rats subjected to pressure or volume overload. J Mol Cell Cardiol 2005; 38: 777-786, doi: 10.1016/j.yjmcc.2005.02.012.

36. Cicogna AC, Robinson KG, Conrad $\mathrm{CH}$, Squire R, Okoshi $\mathrm{MP}$, Bing $\mathrm{OH}$. Role of myocardial contractile status and relaxation in ventricular dysfunction during the transition of heart hypertrophy to failure [in Portuguese]. Arq Bras Cardiol 1997; 69: 381-384, doi: 10.1590/S0066-782X199700120 0003 .

37. Vileigas DF, Deus AF, Silva DCT, Tomasi LC, Campo DHS, Adorni CS, et al. Saturated high-fat diet-induced obesity increases adenylate cyclase of myocardial b-adrenergic system and does not compromise cardiac function. Physiol Rep 2016; 4: e12914, doi: 10.14814/phy2.12914. 
38. Leopoldo AS, Lima-Leopoldo AP, Sugizaki MM, do Nascimento AF, de Campos DH, Luvizotto RAM, et al. Involvement of L-type calcium channel and SERCA2a in myocardial dysfunction induced by obesity. J Cell Physiol 2011; 226: 2934-2942, doi: 10.1002/jcp.22643.
39. Draper NR, Smith H. Applied regression analysis. 3rd ed., New York: John Wiley; 1998, doi: 10.1002/SERIES1345.

40. Locatelli J, Assis LVM, Isoldi MC. Calcium handling proteins: structure, function, and modulation by exercise. Heart Fail Rev 2014; 19: 207-225, doi: 10.1007/s10741-013-9373-z. 